\title{
Hungry for more: key stakeholders' support for more stringent school food policies
}

\author{
Simone Pettigrew ${ }^{1}{ }^{*}$, Zenobia Talati ${ }^{1}$, Megan Sauzier ${ }^{2}$ and Amanda Ferguson ${ }^{2}$ \\ ${ }^{1}$ School of Psychology, Curtin University, Kent Street, Bentley, WA 6102, Australia: ${ }^{2}$ Western Australian School \\ Canteen Association, East Perth, Western Australia, Australia
}

Submitted 28 July 2018: Final revision received 8 November 2018: Accepted 27 November 2018: First published online 8 February 2019

\begin{abstract}
Objective: School food policies are an important component of comprehensive strategies to address child obesity and improve children's health. Evaluations have demonstrated that these policies can be initially well accepted and appropriately implemented, however little is known about how acceptance levels may change over time. The present study aimed to re-evaluate a school food policy 10 years after its introduction to assess key stakeholders' support for various policy extensions that would strengthen the scope of the policy.

Design: Online surveys administered 1 year after policy introduction $(n 607,2008)$ and 10 years after policy introduction ( $n$ 307, 2016).

Setting: Western Australia.

Participants: School principals, teachers, canteen managers and presidents of parents \& citizens associations from Western Australian Government primary schools.

Results: At both time points, and especially at time 2 (10 years post policy implementation), high levels of support were reported for the policy and possible policy extensions. Support was strongest for an additional requirement to integrate the canteen menu with the classroom health curriculum.

Conclusions: The results suggest that once a policy has become embedded into school practices, stakeholders may be receptive to modifications that strengthen the policy to enhance its potential effects on children's diets.
\end{abstract}

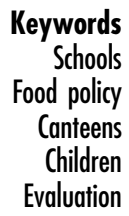

Rates of child obesity are increasing globally ${ }^{(1)}$, prompting governments to consider various strategies to improve children's diets and reduce their risk of obesity and its sequela (for a comprehensive list of relevant initiatives, see the NOURISHING framework developed by the World Cancer Research Fund International ${ }^{(2)}$ ). An important component of these efforts is school food policies that specify the kinds of foods and beverages that can and cannot be sold and supplied on school premises ${ }^{(3,4)}$. The range of foods available for sale at school directly affects children's on-site food purchases; for example, a recent study found a $1.67 \%$ increase in the number of unhealthy foods purchased for every $1 \%$ increase in availability ${ }^{(5)}$.

For new health policies and programmes to be effective, they need to be embraced by stakeholders and appropriately implemented on the ground ${ }^{(3,6)}$. Evidence of stakeholder support, along with support from the broader community, can be a key determinant of whether relevant policy decisions are made ${ }^{(7-10)}$. There is a tendency for policies designed to improve health outcomes for children to achieve higher levels of community support than adultfocused policies ${ }^{(8,11)}$. In addition, there is evidence that nutrition-related policies can be more effective in producing positive outcomes for disadvantaged groups if implemented in schools $v$. other settings ${ }^{(12)}$. However, efforts to formalise changes to school food provision to enforce the provision of healthier options and remove unhealthy options can still face opposition ${ }^{(13)}$, making it important to anticipate potential reactions and the resulting implications for policy implementation. It has been noted that in the context of school food policies it is especially important to assess the reactions of those tasked with policy implementation within schools to (i) identify potential areas of acceptance and resistance and (ii) develop effective approaches and resources to enhance understanding of the benefits of the policy and facilitate implementation ${ }^{(14-16)}$.

Experiences in various health-related public policy domains have demonstrated that new policies generally become more acceptable post-implementation as people 
become accustomed to the new conditions ${ }^{(8)}$. Acceptance is heightened if it is apparent that the policies have been effective $^{(17,18)}$. Previous work has found considerable support for school food policies at the time of their introduction among key stakeholders ${ }^{(13,19-21)}$. Much less is known about whether this support is maintained or changes over time.

While levels of child overweight/obesity in Australia are relatively stable at about $28 \%$ of those aged 5-12 years ${ }^{(22)}$, this prevalence rate remains far too high and further efforts are needed to reduce the number of children affected. The implementation of more stringent healthy food and drink policies in schools is a potential strategy to assist in achieving this outcome. Such policies may positively influence both the types of foods consumed on school premises and children's overall dietary intake ${ }^{(23,24)}$. It is acknowledged that in-school food provision is just one aspect of children's food environments and that other factors such as home and neighbourhood food characteristics will have a substantial influence on nutritionrelated outcomes such as nutrient and energy intakes and adiposity levels, and are therefore also in need of attention $^{(25,26)}$. This is evident in the relatively small number of studies demonstrating significant reductions in child obesity resulting from school food policies that limit the presence of unhealthy 'discretionary' foods and beverages $^{(27,28)}$. However, school food policies represent tools to create supporting healthy eating environments, and positive changes have been identified for other intermediary outcomes such as increased fruit and vegetable intake and reduced consumption of sugar-sweetened beverages $^{(24,29)}$.

The aims of the present study were to: (i) assess key stakeholders' attitudes to a healthy food and drink policy a decade after its introduction in Western Australia; (ii) investigate these stakeholders' receptiveness to various potential policy extensions; and (iii) identify factors associated with higher levels of receptiveness to the introduction of a more stringent version of the policy, to provide insight into potential target areas for future interventions designed to increase support for policy extensions. In addition, given calls for schools to receive greater assistance to achieve high levels of food policy implementation $^{(30)}$, stakeholder interest in a range of potential resources was assessed.

The study builds on prior research investigating stakeholders' perceptions of the Western Australian Department of Education's Healthy Food and Drink Policy shortly after its introduction ${ }^{(13,21)}$ and an analysis of compliance levels 10 years later ${ }^{(31)}$. By assessing stakeholders' attitudes to the policy a decade after its implementation and gauging support for making the policy more stringent, the present study represents one of the few long-term evaluations of school food policies and provides novel insights into the extent to which such policies can be extended over time.

\section{The Western Australian Healthy Food and Drink Policy}

The mandatory Healthy Food and Drink Policy was officially introduced by the Western Australian Department of Education in late 2006 for implementation in the state's 699 public schools in 2007. Reflective of the need for school food policies to be comprehensive in scope and consistent with a 'whole of school' approach ${ }^{(3,32-34)}$, there are five core areas of the Western Australian policy ${ }^{(35)}$ : (i) the development of a school-level healthy food and drink policy; (ii) canteen menus must comprise a minimum of $60 \%$ 'green' items, a maximum of $40 \%$ 'amber' items and no 'red' items as determined by a traffic-light categorisation system; (iii) canteen staff must undertake training in the traffic-light food categorisation system and food safety/ hygiene; (iv) foods and beverages classified as 'red' are not used as classroom rewards or provided as part of school-run events/activities; and (v) the school community is kept informed about the policy (e.g. through newsletters, school websites and/or colour-coded menus).

Subsequently, a national-level voluntary policy was introduced by the federal Health Department in 2010 that closely resembled the Western Australian policy ${ }^{(36)}$. The national policy has since been adopted by several Australian states, but Western Australia has retained its mandatory policy that is largely consistent with the national policy with some additional elements that make it more stringent. For example, Western Australia is the only jurisdiction to set specific targets for 'green' $(\geq 60 \%)$ and 'amber' $(\leq 40 \%)$ products and to require school principals to report annually on compliance to the Western Australian Department of Education ${ }^{(30)}$.

In an evaluation of the Western Australian policy that was conducted about a year after its introduction ${ }^{(13,21)}$, high levels of support were found among key stakeholder groups including school principals, teachers, canteen managers and presidents of parents and citizens (P\&C) associations (the latter are typically tasked with managing school canteens in Western Australian public schools). The results of a subsequent 10-year follow-up evaluation showed that about $80 \%$ of schools reported being compliant with all aspects of the policy and that a large majority of respondents believed the policy has improved the healthiness of foods and drinks provided in schools (85\%) and constitutes a good opportunity to teach children about healthy eating $(90 \%)^{(31)}$.

In the original evaluation, many respondents indicated endorsement of various policy extensions, with most support expressed for linking the canteen menu with the health curriculum, providing seating areas for children to eat their meals, ensuring foods offered are free of preservatives and additives and pricing foods according to their healthiness ${ }^{(21)}$. To date, these additional components have not been incorporated into the policy and instead individual schools determine whether they will be 
implemented on their premises. Comparing these early results with the 10-year follow-up data, the present study examines the extent to which schools may have implemented these optional changes and/or continue to support their potential inclusion in the policy. The results provide policy makers with an indication of the types of additional policy components that are likely to be considered feasible and acceptable.

\section{Methods}

\section{Participants}

In both the 1-year and 10-year evaluations, a voluntary online survey was administered to the following key stakeholder groups in Western Australian public schools: school principals, teachers, canteen managers and presidents of P\&C associations. Principals of Western Australian public schools have ultimate responsibility for policy implementation and, as noted above, are required to report on policy compliance annually. Teachers also have a role to play in policy implementation due to the requirement to avoid using 'red' foods and beverages to reward students. Canteen managers and $\mathrm{P} \& \mathrm{C}$ association presidents typically have joint operational responsibility for policy implementation via menu design and canteen management.

For the 1-year evaluation in 2008, the survey was disseminated via a single-purpose email directly to all public school principals that was accompanied by a request to forward the survey link to two teachers in their school, the canteen manager and the P\&C president. Due to permission restrictions, the invitation to participate in the 2016 survey was incorporated into a group-distribution email containing numerous other news items sent by the Western Australian Department of Education to public school principals.

\section{Instrumentation}

To permit comparisons between the 2008 and 2016 results, the 2016 survey contained many of the same items from the initial policy evaluation survey that had been developed specifically for that study ${ }^{(21)}$. These included descriptive items relating to role (principal, teacher, canteen manager, $\mathrm{P} \& \mathrm{C}$ president), school type (primary, secondary, other) and school location (metropolitan, regional), along with self-reported current level of school compliance with the policy (rated on a 5-point scale from 'non-compliant' to 'fully compliant'). In addition, respondents were asked to report the extent to which they were committed to meeting and exceeding the minimum requirements (rated on a 5-point scale from 'strongly disagree' to 'strongly agree'), their attitudes to a range of potential policy extensions and their preferences for various forms of support that would enable them to effectively implement an enhanced version of the policy. An example of exceeding the policy requirements provided to respondents was increasing the minimum proportion of 'green' items required on the menu (currently $60 \%$ ). Suggested policy extensions included those relating to the types of foods offered (e.g. organic foods), available infrastructure (e.g. seating areas of children) and the promotion and pricing of menu items. Listed forms of possible support included advertising materials to be displayed in the canteen and resources designed for key stakeholders including teachers, parents and children.

\section{Data analysis}

Data from the 2008 and 2016 data sets were analysed using the statistical software package IBM SPSS Statistics version 24. Descriptive statistics were calculated to show the proportion of respondents: (i) falling into different demographic categories; (ii) who were motivated to meet policy requirements; (iii) who were motivated to exceed policy requirements; (iv) who preferred different policy extensions; and (v) who preferred various forms of policy support. $Z$-scores and the associated $P$ values were used to test for significant differences in demographics across the two data sets. The $t$ test and one-way ANOVA (with Tukey's honestly significant difference test for post hoc comparison) were used to test for significant differences between the two data sets for the remaining variables. Finally, a linear regression was used to examine predictors of respondents' motivation to exceed policy requirements.

\section{Results}

In total, 607 stakeholders (from 699 schools) responded to the 2008 survey and 307 (from 798 schools) responded to the 2016 survey. While the latter sample was smaller in size, the stakeholder compositions of the samples were similar across the two surveys (see Table 1). It was not possible to determine the overall response rate due to the multiple potential respondents from each school and the likelihood that different schools were represented by different types of respondent (e.g. only the canteen manager may have responded from one school while all four categories of respondent may have participated from another). However, as a general indication of relative response rates across surveys, the number of principals responding as a proportion of the total number of schools in the state at each time point was $44 \%$ (311 principals) for the initial survey and 14\% (116 principals) for the followup survey.

Table 2 shows the reported motivation of respondents completing the 2016 survey to meet and/or exceed the policy's requirements. More than three-quarters (84\%) of respondents indicated that they were motivated to comply with the current policy requirements and two-thirds (65\%) 
Table 1 Sample profile of respondents to the online survey about the Healthy Food and Drink Policy in Western Australian public schools at the initial 1-year post-implementation evaluation (2008) and the 10-year follow-up evaluation (2016)

\begin{tabular}{lcc}
\hline & $\begin{array}{c}2008 \\
(n 607)\end{array}$ & $\begin{array}{c}2016 \\
(n 307)\end{array}$ \\
\cline { 2 - 3 } & $\%$ & $\%$ \\
\hline Stakeholder group & 51 & \\
Principals & 24 & $38^{\star *}$ \\
Teachers & 14 & 26 \\
Canteen managers & 11 & $19^{*}$ \\
P\&C association presidents & 70 & $17^{\star *}$ \\
School type & 21 & 76 \\
Primary & 9 & 17 \\
Secondary & & 7 \\
Other & 65 & $58^{*}$ \\
School location & 35 & $42^{*}$ \\
Metropolitan & & \\
Regional & & \\
\hline
\end{tabular}

$\mathrm{P} \& \mathrm{C}$, parents and citizens.

'Other' category includes schools that are combined primary/secondary schools or remote schools.

Significant difference between 2008 and 2016 (assessed via the $t$ test): ${ }^{\star} P<0.05,{ }^{\star \star} P<0.01$.

reported being motivated to exceed them. Of the various categories of respondent, canteen managers reported the highest level of motivation to exceed policy requirements (76\%).

Very high levels of support were expressed for most of the proposed policy extensions listed in Table 3. As was found in the 2008 evaluation, the most popular extensions in 2016 were to explicitly link the school canteen menu with the health curriculum (83\% expressing support), to exclude foods containing preservatives and food additives (78\%) and to price products according to their healthiness ( $72 \%)$. The only potential extension that did not receive majority support was for organic foods to be sold in the canteen (40\%). All potential extensions had larger levels of support in 2016 relative to 2008, with these increases statistically significant in all cases except for the provision of preservative/additive-free foods $(P=0.07)$ and seating areas for children $(P=0 \cdot 07)$.

When asked about additional resources that could assist schools to comply with the policy, high levels of support were found for all suggested support options, ranging from $64 \%$ endorsing actions to increase interaction between canteen managers and teachers to $80 \%$ endorsing the provision of information for parents about the way the traffic-light food categorisation system is used in schools (Table 4). Significantly higher levels of interest were expressed in 2016 relative to 2008 for three areas of support: (i) developing student assignments on the topic of promoting healthy menu items; (ii) providing information for parents about the traffic-light system; and (iii) offering healthy lunchbox workshops for parents.

A linear regression was conducted to identify factors associated with motivation to exceed minimum policy compliance. Factors included in the model were school type (primary, secondary), school location (metropolitan, regional), number of students enrolled at the school, days per week of canteen operation, current level of compliance (rated on a 5-point scale from 'non-compliant' to 'fully compliant'), number of policy extensions endorsed (as listed in Table 3) and canteen profitability (profitable/ breakeven, loss/unsure). Motivation to exceed current policy requirements was significantly associated with level of compliance with the current policy. Endorsement of a larger number of policy extensions, the number of days per week of canteen operations, school type, school size, school location and canteen profitability were not associated with motivation to exceed current requirements.

\section{Discussion}

The results of the present study provide support for the proposition that school food policies can experience stronger support after they have been in place for some time. This outcome is consistent with prior research in other domains indicating that public support for policies can increase post-implementation. In particular, support has been found to be stronger where policies are perceived to be effective, consistent with prevailing social norms and targeting vulnerable groups, especially children ${ }^{(8,17,18)}$. However, while there is a growing evidence base on levels of public support for a wide range of existing and potential health-related policies, there appears to be a lack of research examining attitudes to the same potential policy extensions over time among those stakeholder groups tasked with policy implementation.

Extending previous research, the present results suggest that there may also be increasing support among key stakeholders for making school food policies more strin-

Table 2 Motivation to meet/exceed policy requirements expressed by respondents to the online survey about the Healthy Food and Drink Policy in Western Australian public schools at the 10-year follow-up evaluation (2016)

\begin{tabular}{lccccc}
\hline Motivation & $\begin{array}{c}\text { Principals } \\
(\%) \dagger\end{array}$ & $\begin{array}{c}\text { Teachers } \\
(\%) \dagger\end{array}$ & $\begin{array}{c}\text { Canteen managers } \\
(\%) \dagger\end{array}$ & $\begin{array}{c}\text { P\&C association presidents } \\
(\%) \dagger\end{array}$ & $\begin{array}{c}\text { Total sample } \\
(\%) \dagger\end{array}$ \\
\hline $\begin{array}{l}\text { To meet policy requirements } \\
\text { To exceed policy } \\
\text { requirements }\end{array}$ & 87 & 79 & 84 & 84 & 84 \\
& 69 & 55 & 76 & 58 & 65 \\
\hline
\end{tabular}

$\mathrm{P} \& \mathrm{C}$, parents and citizens.

†Those selecting 4 or 5 on a 5 -point scale, from $1=$ 'strongly disagree' to $5=$ 'strongly agree'. No significant differences were found among the different stakeholder groups (assessed via ANOVA). 
Table 3 Stakeholders' views on possible policy extensions to the Healthy Food and Drink Policy in Western Australian public schools at the initial 1-year post-implementation evaluation (2008) and the 10-year follow-up evaluation (2016)

\begin{tabular}{|c|c|c|c|c|c|c|c|c|c|c|c|c|}
\hline & \multirow{3}{*}{$\begin{array}{c}\text { Already implemented } \\
\begin{array}{c}\text { Total sample } \\
(\%)\end{array} \\
2016\end{array}$} & \multicolumn{11}{|c|}{ Desired policy extension by stakeholder group $\dagger$} \\
\hline & & \multicolumn{2}{|c|}{$\begin{array}{l}\text { Principals } \\
\quad(\%) \ddagger\end{array}$} & \multicolumn{2}{|c|}{$\begin{array}{l}\text { Teachers } \\
\text { (\%) } \ddagger\end{array}$} & \multicolumn{2}{|c|}{$\begin{array}{l}\text { Canteen } \\
\text { managers } \\
(\%) \ddagger\end{array}$} & \multicolumn{2}{|c|}{$\begin{array}{l}\mathrm{P} \& \mathrm{C} \text { association } \\
\text { presidents } \\
(\%) \ddagger\end{array}$} & \multicolumn{2}{|c|}{$\begin{array}{l}\text { Total sample } \\
\text { (\%) } \ddagger\end{array}$} & \multirow[b]{2}{*}{ Cohen's $d$} \\
\hline & & 2008 & 2016 & 2008 & 2016 & 2008 & 2016 & 2008 & 2016 & 2008 & 2016 & \\
\hline $\begin{array}{l}\text { Menu consistent with the classroom } \\
\text { health curriculum }\end{array}$ & 15 & 77 & 85 & 79 & 91 & 74 & 78 & 63 & 68 & 76 & $83^{\star \star}$ & 0.22 \\
\hline Seating areas for children & 42 & 59 & 67 & 57 & 71 & 50 & 63 & 65 & 58 & 58 & 65 & - \\
\hline Preservative/additive-free foods & 8 & 75 & 77 & 83 & 88 & 73 & 63 & 64 & 79 & 75 & 78 & - \\
\hline Foods priced by healthiness & 11 & 67 & 71 & 72 & 85 & 47 & 68 & 67 & 58 & 65 & $72^{\star \star}$ & 0.41 \\
\hline $\begin{array}{l}\text { Healthy eating information in school } \\
\text { newsletter }\end{array}$ & 14 & 50 & 78 & 62 & 81 & 47 & 60 & 45 & 53 & 51 & $70^{\star *}$ & 0.26 \\
\hline Prioritising local foods/produce & 10 & 57 & 67 & 77 & 81 & 62 & 56 & 58 & 62 & 62 & $68^{* *}$ & 0.24 \\
\hline Organic foods & 3 & 32 & $41^{\mathrm{a}}$ & 40 & $50^{\mathrm{b}}$ & 24 & $33^{\mathrm{a}}$ & 20 & $30^{c}$ & 31 & $40^{\star \star}$ & 0.24 \\
\hline
\end{tabular}

\section{$\mathrm{P} \& \mathrm{C}$, parents and citizens.}

a,b,c, Mean values within a row with unlike superscript letters were significantly different between stakeholder groups completing the survey in 2016 (assessed via ANOVA with Tukey's honestly significant difference test for post hoc comparison): $P<0.05$

Significant difference between 2008 and 2016 (assessed via the $t$ test): ${ }^{*} P<0.01$.

Excluding respondents who reported already implementing these policy extensions.

Those selecting 4 or 5 on a 5 -point scale, from $1=$ 'don't want it at all' to $5=$ 'want it very much' 
Table 4 Stakeholders' preferences for various types of additional policy support for the Healthy Food and Drink Policy in Western Australian public schools at the initial post-implementation evaluation (2008) and the 10-year follow-up evaluation (2016)

\begin{tabular}{|c|c|c|c|c|c|c|c|c|c|c|c|}
\hline & \multicolumn{2}{|c|}{$\begin{array}{c}\text { Principals } \\
(\%) \dagger\end{array}$} & \multicolumn{2}{|c|}{$\begin{array}{l}\text { Teachers } \\
(\%) \dagger\end{array}$} & \multicolumn{2}{|c|}{$\begin{array}{c}\text { Canteen } \\
\text { managers } \\
(\%) \dagger\end{array}$} & \multicolumn{2}{|c|}{$\begin{array}{c}\mathrm{P} \& \mathrm{C} \text { association } \\
\text { presidents } \\
(\%) \dagger\end{array}$} & \multicolumn{2}{|c|}{$\begin{array}{c}\text { Total } \\
\text { sample } \\
(\%) \dagger\end{array}$} & \multirow[b]{2}{*}{ Cohen's $d$} \\
\hline & 2008 & 2016 & 2008 & 2016 & 2008 & 2016 & 2008 & 2016 & 2008 & 2016 & \\
\hline Information for parents about how traffic-light system used at school & 72 & 75 & 82 & 93 & 71 & 69 & 69 & 80 & 73 & $80^{*}$ & 0.19 \\
\hline Student assignments about promoting healthy menu items & 60 & 73 & 66 & 85 & 64 & 69 & 76 & - & 64 & $76^{\star \star}$ & 0.29 \\
\hline Providing advertising materials for green items & 75 & 67 & 85 & 81 & 78 & 71 & 75 & 80 & 78 & 74 & - \\
\hline Information for parents about how to use the traffic-light system at home & 77 & $73^{\mathrm{a}}$ & 84 & $90^{\mathrm{b}}$ & 55 & $61^{\mathrm{c}}$ & 73 & $58^{\mathrm{C}}$ & 75 & 73 & - \\
\hline Healthy lunchbox workshops for parents & 71 & $73^{\mathrm{a}}$ & 76 & $86^{\mathrm{b}}$ & 42 & $55^{\mathrm{c}}$ & 60 & $73^{\mathrm{a}}$ & 66 & $73^{*}$ & 0.18 \\
\hline Encouraging interaction between canteen managers and teachers to facilitate healthy eating education & 60 & 62 & 69 & 74 & 60 & 53 & 62 & 62 & 62 & 64 & - \\
\hline
\end{tabular}

\section{$\mathrm{P} \& \mathrm{C}$, parents and citizens}

a,b,c Mean values within a row with unlike superscript letters were significantly different between stakeholder groups completing the survey in 2016 (assessed via ANOVA with Tukey's honestly significant difference test for post hoc comparison): $P<0.05$

2008 and 2016 (assessed via the $t$ test): ${ }^{*} P<0.05,{ }^{* *} P<0.01$

†Those selecting 4 or 5 on a 5 -point scale, from $1=$ 'strongly disagree' to $5=$ 'strongly agree'. 
gent over time. Two-thirds of respondents reported being motivated to exceed the requirements of the current policy and six of the seven potential policy extensions received majority support. Of note is that canteen managers reported the highest levels of motivation to exceed policy requirements $(76 \%)$, which is promising given that this group would be likely to be required to implement many of the changes.

Consistent with the earlier evaluation ${ }^{(13,21)}$, most of the proposed policy extensions received majority support across the four stakeholder groups. The most popular extensions related to enhancing the pedagogical potential of the policy, excluding foods with additives/preservatives and pricing items in accordance with their relative healthiness. The two extensions with the lowest levels of support were providing organic menu items (40\%) and providing seating areas for children (65\%). The relatively low support for organic menu items is likely to be primarily due to the substantially higher cost and more limited availability of organic produce in Australia ${ }^{(37)}$. In the case of seating areas, this variable had the highest 'already implemented' level ( $42 \%)$, which may have resulted in some schools seeing this as a non-essential element of the policy.

For the more stringent school food policies of the future to meet their potential to improve children's diets, various forms of implementation assistance are likely to be nee$\operatorname{ded}^{(35)}$. The stakeholders involved in the present study were very receptive to a range of possible resources that could assist them to meet and/or exceed current policy requirements. This is consistent with previous research highlighting the importance of such resources in determining schools' ability to comply with healthy food policies $^{(15)}$. The level of interest in the nominated resources was high in both the 2008 and 2016 surveys, with between about two-thirds and more than three-quarters of respondents in both time periods indicating that the suggested curriculum, parent and food promotion resources would be useful. There are therefore likely to be simple, concrete means by which governments can enhance compliance with existing school food policies and lay the ground for future policy extensions by suggesting strategies and providing schools with additional resources and strategies to facilitate closer integration of the policy into school practices and school-home interactions ${ }^{(38)}$. In addition, it may be possible to increase receptiveness to policy enhancements by framing any changes in terms of the additional support that would be provided to assist stakeholders with implementation of the scaled-up policy requirements.

The results show that those schools reporting the highest levels of compliance with the policy were most likely to be motivated to exceed the policy requirements. The lack of difference according to days of canteen operation, school type, location or size is encouraging, because this suggests that strategies employed to increase compliance levels and promote implementation beyond the scope of the policy do not need to be varied by these characteristics. This should simplify the process of developing resources designed to assist schools to optimise the positive outcomes that can be achieved through the introduction and enhancement of school food policies. It is important that any resulting resources are perceived to be appropriate and useful by the relevant stakeholders, and that efforts are made to ensure that those who could benefit from the resources are made aware of their availability $^{(14)}$.

In addition to policy-level implications, the study results highlight factors that schools can consider when developing their own health and well-being plans. The potential policy extensions listed in Table 3 constitute practices that schools may wish to implement at the local level and the strategies listed in Table 4 represent activities that could be undertaken to facilitate successful implementation of these local-level plans. Given the varying cost implications of different practices and strategies, those that require fewer resources could be initially prioritised. Examples include (i) encouraging interaction between canteen managers and teachers to facilitate curriculum activities about healthy eating and (ii) setting student assignments focused on developing strategies and materials to promote healthy menu items. Providing parents with information about how foods are selected for inclusion in the canteen menu is also likely to be a relatively inexpensive and straightforward initiative. Schools may wish to advocate for government policies to formalise and fund those additional policy elements they consider have the most potential to improve outcomes for their students.

\section{Limitations}

While a strength of the present study is the assessment of attitudes to potential school food policy extensions at two time points, primary limitations include the smaller sample in the 10-year follow-up survey and the anonymous nature of the data preventing direct comparisons between the two cohorts. The smaller sample in 2016 is likely to be a function of the somewhat different recruitment methods used in the two survey waves. Although both survey participation invitation emails were extended by the Western Australian Department of Education, the 2008 survey invitation was extended via a single-purpose email while the invitation for the 2016 survey was contained within an email featuring numerous information items with which the survey notice had to compete for attention. This may have resulted in a greater proportion of respondents with a specific interest in the policy responding to the second survey. In both waves, the dissemination process via email to principals prevented calculation of total response rates because information relating to the number of principals who opened the emails and the number of 
other stakeholders to whom they forwarded the link was unavailable.

A further limitation was the inability to include parents in the follow-up study due to funding constraints, despite their involvement in the original evaluation. Parents demonstrated even stronger support for policy extensions than the other stakeholders soon after policy introduction $^{(21)}$ and as such it would be of interest to determine whether their attitudes improved from this higher base. Future research could also consider the views of children and whether they similarly become more positive about school food policies over time.

\section{Conclusions}

This follow-up evaluation of a school food policy indicates that once a policy has become embedded into school practices, stakeholders may be receptive to modifications that strengthen the policy to increase its potential effects on children's diets. This apparent increase in support for more stringent policies is a positive outcome because it provides policy makers with a degree of assurance that future policy enhancements would be readily accepted and implemented ${ }^{(10)}$. The ability to evolve school food policies and related support over time is important to ensure increasingly strong action can be taken to improve children's diets and potentially address continuing high rates of child obesity.

\section{Acknowledgements}

Financial support: The implementation and evaluation of the Western Australian Healthy Food and Drink Policy is funded by the Western Australia Department of Health and the Western Australian Department of Education. Conflict of interest: M.S. and A.F. are employees of the Western Australian Department of Education and S.P. and Z.T. are employed in a university research unit contracted to evaluate the Healthy Food and Drink Policy. Authorship: S.P. conceptualised the study, managed data collection and took primary responsibility for preparing the manuscript. Z.T. performed the data analysis. M.S. and A.F. assisted with developing the instrument, preparing the instrument and providing technical advice on the policy. All authors contributed to the preparation of the manuscript and approved its publication. Ethics of buman subject participation: This study was conducted according to the guidelines laid down in the Declaration of Helsinki and all procedures involving human subjects were approved by the Western Australian Department of Education and the Curtin University Human Research Ethics Committee. Informed consent was obtained from all study participants.

\section{References}

1. World Health Organization (2017) Facts and figures on childhood obesity. http://www.who.int/end-childhoodobesity/facts/en/ (accessed January 2018).

2. World Cancer Research Fund International (2018) NOURISHING framework. http://www.wcrf.org/int/policy/nour ishing-framework (accessed January 2018).

3. Hawkes C, Smith TG, Jewell J et al. (2015) Smart food policies for obesity prevention. Lancet 385, 2410-2421.

4. Mahesh R, Vandevijvere S, Dominick C et al. (2018) Relative contributions of recommended food environment policies to improve population nutrition: results from a Delphi study with international food policy experts. Public Health Nutr 21, 2142-2148.

5. Clinton-McHarg T, Janssen L, Delaney T et al. (2018) Availability of food and beverage items on school canteen menus and association with items purchased by children of primary-school age. Public Health Nutr 21, 2907-2914.

6. Snelling A, Belson SI, Watts E et al. (2017) Measuring the implementation of a school wellness policy. $J$ Sch Health 87, 760-768.

7. Baum F \& Fisher M (2014) Why behavioural health promotion endures despite its failure to reduce health inequities. Sociol Health Illn 36, 213-225.

8. Diepeveen S, Ling T, Suhrcke M et al. (2013) Public acceptability of government intervention to change healthrelated behaviours: a systematic review and narrative synthesis. BMC Public Health 13, 756.

9. Hirschman J \& Chriqui JF (2013) School food and nutrition policy, monitoring and evaluation in the USA. Public Health Nutr 16, 982-988.

10. Reisch LA, Sunstein CR \& Gwozdz W (2017) Beyond carrots and sticks: Europeans support health nudges. Food Policy 69, $1-10$.

11. Mazzocchi M, Cagnone S, Bech-Larsen T et al. (2015) What is the public appetite for healthy eating policies? Evidence from a cross-European survey. Health Econ Policy Law 10, 267-292.

12. Olstad DL, Ancilotto R, Teychenne M et al. (2017) Can targeted policies reduce obesity and improve obesity-related behaviours in socioeconomically disadvantaged populations? A systematic review. Obes Rev 18, 791-807.

13. Pettigrew S, Pescud M \& Donovan RJ (2012) Stakeholder perceptions of a comprehensive school food policy in Western Australia. Health Policy 108, 100-104.

14. Levay AV, Chapman GE, Seed B et al. (2018) It's just the right thing to do: conceptualizing a theory of change for a school food and beverage sales environment intervention and implications for implementation evaluation. Eval Program Plan 70, 73-82.

15. Reilly KL, Nathan N, Wiggers J et al. (2018) Scale up of a multi-strategic intervention to increase implementation of a school healthy canteen policy: findings of an intervention trial. BMC Public Health 18, 860.

16. Reilly KL, Reeves P, Deeming $\mathrm{S}$ et al. (2018) Economic analysis of three interventions of different intensity in improving school implementation of a government healthy canteen policy in Australia: costs, incremental and relative cost effectiveness. BMC Public Health 18, 378.

17. Drews S \& Van den Bergh JC (2016) What explains public support for climate policies? A review of empirical and experimental studies. Clim Policy 16, 855-876.

18. Jagers SC, Matti S \& Nilsson A (2017) How exposure to policy tools transforms the mechanisms behind public acceptability and acceptance - the case of the Gothenburg congestion tax. Int J Sustain Transport 11, 109-119.

19. Asada Y, Ziemann M, Zatz L et al. (2017) Successes and challenges in school meal reform: qualitative insights from food service directors. J Sch Health 87, 608-615. 
20. Dick M, Lee A, Bright M et al. (2012) Evaluation of implementation of a healthy food and drink supply strategy throughout the whole school environment in Queensland state schools, Australia. Eur J Clin Nutr 66, 1124-1129.

21. Pettigrew S, Pescud M \& Donovan RJ (2012) Stakeholder support for school food policy expansions. Health Educ Res 27, 996-1004

22. Australian Institute of Health and Welfare (2018) Australia's Health 2018. Australia's Health Series no. 16. AUS 221. Canberra: AIHW.

23. Adamson A, Spence S, Reed L et al. (2013) School food standards in the UK: implementation and evaluation. Public Health Nutr 16, 968-981.

24. Micha R, Karageorgou D, Bakogianni et al. (2018) Effectiveness of school food environment policies on children's dietary behaviors: a systematic review and meta-analysis. PLoS One 13, e0194555.

25. Fitzpatrick C, Datta GD, Henderson M et al. (2017) School food environments associated with adiposity in Canadian children. Int J Obes (Lond) 41, 1005-1010.

26. Spence S, Delve J, Stamp E et al. (2014) Did school food and nutrient-based standards in England impact on 11-12 y olds nutrient intake at lunchtime and in total diet? Repeat crosssectional study. PLoS One 9, e112648.

27. Datar A \& Nicosia N (2017) The effect of state competitive food and beverage regulations on childhood overweight and obesity. J Adolesc Health 60, 520-527.

28. Dority BL, McGarvey MG \& Kennedy PF (2010) Marketing foods and beverages in schools: the effect of school food policy on students' overweight measures. J Public Policy Mark 29, 204-218.

29. Vézina-Im L, Beaulieu D, Bélanger-Gravel A et al. (2017) Efficacy of school-based interventions aimed at decreasing sugar-sweetened beverage consumption among adolescents: a systematic review. Public Health Nutr 20, 2416-2431.
30. Wu JHY, Berg J \& Neeson M (2016) Overview of development and implementation of school canteen nutrition guidelines in Australia.J Home Econ Inst Aust 23, 2.

31. Pettigrew S, Talati Z, Sauzier M et al. (2018) Stakeholder perceptions of a school food policy ten years on. Public Health Nutr 21, 1370-1374.

32. Hayes D, Contento IR \& Weekly C (2018) Position of the Academy of Nutrition and Dietetics, Society for Nutrition Education and Behavior, and School Nutrition Association: comprehensive nutrition programs and services in schools. J Acad Nutr Diet 18, 913-919.

33. McIsaac JL, Hernandez KJ, Kirk SF et al. (2016) Interventions to support system-level implementation of health promoting schools: a scoping review. Int J Environ Res Public Health 13, 200 .

34. Welker E, Lott M \& Story M (2016) The school food environment and obesity prevention: progress over the last decade. Curr Obes Rep 5, 145-155.

35. Government of Western Australia (2016) Healthy Food and Drink Policy. http://det.wa.edu.au/policies/detcms/policyplanning-and-accountability/policies-framework/policies/ healthy-food-and-drink-policy.en?cat-id=3457102 (accessed June 2017).

36. Commonwealth of Australia (2013) 2010 National Healthy School Canteens Guidelines. http://www.health.gov.au/ internet/main/publishing.nsf/content/phd-nutrition-canteens (accessed June 2017).

37. O'Mahony B \& Lobo A (2017) The organic industry in Australia: current and future trends. Land Use Policy 66 , 331-339.

38. Kehm R, Davey CS \& Nanney MS (2015) The role of family and community involvement in the development and implementation of school nutrition and physical activity policy. $J$ Sch Health $\mathbf{8 5}$, 90-99. 